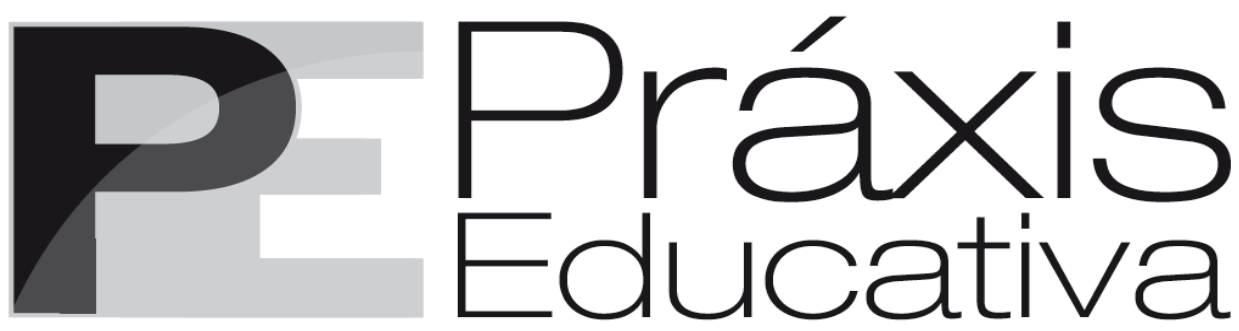

ISSN 1809-4031

eISSN 1809-4309

https://doi.org/10.5212/PraxEduc.v.16.18474.077

Seção: Artigos

\title{
Educação Superior: as emoções e o processo de ensino-aprendizagem
}

\section{Higher Education: emotions and the teaching-learning process}

\section{Educación Superior: las emociones y el proceso de enseñanza-aprendizaje}

\author{
Claudia Dallagnol ${ }^{*}$ \\ iD https://orcid.org/0000-0002-4506-1806 \\ Ivete Janice de Oliveira Brotto** \\ (D) https://orcid.org/0000-0002-7892-2190
}

\begin{abstract}
Resumo: Este estudo apresenta os resultados de uma pesquisa de mestrado que investigou os motivos que conduziram graduandos a buscar atendimento psicológico e estabeleceu relações destes motivos com o processo de ensino-aprendizagem. Os dados foram obtidos por meio de questionário, aplicado a 30 estudantes de 18 anos ou mais, em um campus universitário federal, do interior do estado do Paraná, Brasil. A investigação foi de caráter qualitativo e exploratório. Os dados foram sistematizados e analisados por meio da análise de conteúdo de Bardin, sendo fundamentados a partir da Psicologia Histórico-Cultural e da perspectiva bakhtiniana da linguagem. Os resultados enalteceram diferentes motivos, que foram organizados em quatro categorias temáticas: mudanças na condição de vida, adaptação acadêmica/escolha profissional, impacto/reações emocionais e processo de ensino-aprendizagem. Os motivos da procura pelo atendimento psicológico demonstraram relação com os estados emocionais apresentados pelos estudantes e indicaram incidir significativamente sobre a condição de aprendizagem.
\end{abstract}

Palavras-chave: Emoções. Educação Superior. Ensino-aprendizagem.

Abstract: This study presents the results of a master's degree research that investigated the reasons that led undergraduate students to seek psychological care and established relationships between these reasons and the teaching-learning process. The data were obtained through a questionnaire, applied to 30 students aged 18 years or older, on a federal university campus in the interior of the state of Paraná, Brazil. The investigation was qualitative and exploratory. The data were systematized and analyzed using Bardin's content analysis, based on Cultural-Historical Psychology and the Bakhtinian perspective of language. The results highlighted different reasons, which were organized into four thematic categories: changes in living conditions, academic adaptation/professional choice, impact/emotional reactions, and the teaching-

\footnotetext{
* Mestre em Educação pela Universidade Estadual do Oeste do Paraná e psicóloga da Universidade Federal da Fronteira Sul. E-mail: <claudia_dallagnol@hotmail.com>.

** Doutora em Educação pela Universidade Federal do Paraná e professora aposentada da Universidade Estadual do Oeste do Paraná. E-mail: <ibrotto@hotmail.com>.
}

Práxis Educativa, Ponta Grossa, v. 16, e2118474, p. 1-16, 2021 Disponível em: < https:// revistas2.uepg.br/index.php/praxiseducativa $>$ 
learning process. The reasons for seeking psychological assistance showed a relationship with the emotional states presented by the students and indicated a significant impact on the learning condition.

Keywords: Emotions. Higher Education. Teaching-Learning.

Resumen: Este estudio presenta los resultados de una investigación de máster que investigó las razones que llevaron estudiantes de graduación a buscar atención psicológica y estableció relaciones de esas razones con el proceso de enseñanza-aprendizaje. Los datos fueron obtenidos por medio de cuestionario, aplicado a 30 estudiantes de 18 años o más, en un campus universitario federal, del interior del estado de Paraná, en Brasil. La investigación fue cualitativa y exploratoria. Los datos fueron sistematizados y analizados por medio del análisis de contenido de Bardin, basándose en la Psicología Histórico-Cultural y la perspectiva bajtiniana del lenguaje. Los resultados destacaron diferentes razones que fueron organizadas en cuatro categorías temáticas: cambios en la condición de vida, adaptación académica/elección profesional, impacto/reacciones emocionales y proceso de enseñanza-aprendizaje. Las razones de la busca por la atención psicológica demostraron relación con los estados emocionales presentados por los estudiantes e indicaron un impacto significativo sobre la condición de aprendizaje.

Palabras clave: Emociones. Educación Superior. Enseñanza-aprendizaje.

\section{Introdução}

A Educação Superior no Brasil teve expansão significativa após o ano 2000. A partir de 2001, com o Plano Nacional de Educação - PNE e suas metas para o aumento dos investimentos na área e a ampliação do quantitativo de estudantes atendidos, deu início o expressivo crescimento das instituições federais. Em 2002, o país contava com 45 universidades federais e 148 campi, já, em 2014, totalizava 63 universidades e 321 campi (BRASIL, 2014).

Para tanto, programas foram criados a fim de atingir as metas de expansão desse nível de ensino. Inicialmente ocorreu a implantação do programa de Expansão I, com o objetivo de interiorizar a Educação Superior pública federal, no período de 2003 a 2007. E, na sequência, o Programa de Apoio à Reestruturação e Expansão das Universidades Federais - REUNI foi criado com vistas à consolidação da proposta de expansão da Educação Superior pública (BRASIL, 2012).

O REUNI foi instituído a partir do Decreto nº 6.096 (BRASIL, 2007a) e teve como objetivo criar condições para a melhoria do acesso e da permanência de estudantes nos cursos de graduação. Como meta, visou aumentar o índice de conclusão dos cursos presenciais, a fim de obter melhor aproveitamento de recursos físicos e humanos nas universidades federais.

O REUNI apresentou como diretrizes: redução da evasão, aumento do ingresso prioritariamente no período noturno e ocupação de vagas ociosas; ampliação da mobilidade acadêmica; revisão dos cursos com atualização de metodologias de ensino-aprendizagem para melhoria da qualidade; diversidade de graduações, sem prioridade às profissionalizações precoces e especializadas; ampliação das políticas para inclusão e assistência estudantil; e articulação entre a graduação e a pós-graduação e entre Educação Superior e Educação Básica (BRASIL, 2007a).

A partir dos referidos dispositivos legais, ocorreu um grande movimento do Estado brasileiro que o direcionou para a ampliação de seu desenvolvimento na área da Educação Superior e, consequentemente, atuou em condições fragilizadas da oferta de ensino, que até o momento caracterizava-se também por um perfil mais elitista e passou a acolher os sujeitos mais desfavorecidos socialmente. Com o relatório produzido pelo Ministério da Educação - MEC referente ao primeiro ano da implantação do REUNI, evidenciou-se o aumento do número de vagas ofertadas ao Ensino Superior federal, superando a meta estipulada para o período. Também, houve destaque para a ampliação do quadro de servidores, tanto professores quanto técnicos

Práxis Educativa, Ponta Grossa, v. 16, e2118474, p. 1-16, 2021 
administrativos em educação, parte das estratégias para cumprir as metas e diretrizes do Programa (BRASIL, 2009).

Em sequência às ações de ampliação das condições de permanência dos estudantes, o Estado brasileiro publicou a portaria normativa $\mathrm{n}^{\circ} 39$, de 12 de dezembro de 2007, que trata da criação do Programa Nacional de Assistência Estudantil - PNAES (BRASIL, 2007b). O PNAES tem como objetivos: democratizar as condições ofertadas aos jovens no que se refere a permanência; reduzir as desigualdades sociais e regionais para a permanência e conclusão da graduação; minimizar a retenção e a evasão; além de promover a inclusão social por meio da educação (BRASIL, 2010).

Com a divulgação do PNAES, observa-se a preocupação focada no estudante, para que este tenha melhores condições de estar na universidade, especialmente por meio da redução dos fatores sociais que prejudicam a condição de permanência. Desse modo, as ações previstas incluíram as seguintes áreas: moradia estudantil; alimentação; transporte; atenção à saúde; inclusão digital; cultura; esporte; creche; apoio pedagógico; e a inclusão dos estudantes com deficiência, transtornos globais do desenvolvimento e altas habilidades e superdotação (BRASIL, 2010).

Quanto as ações vinculadas a atenção à saúde prevista no PNAES, observa-se a demanda por atendimento psicológico por parte dos graduandos. Uma pesquisa em nível nacional realizada nas Instituições Federais de Ensino Superior - IFES, com objetivo de verificar o perfil dos graduandos, indicou que mais de 30\% dos participantes já procuraram atendimento psicológico ao menos uma vez na vida, não esclarecido se interno ou externo à universidade (FONAPRACE, 2016).

Ainda, com a expansão da Educação Superior observa-se a ampliação da possibilidade de mais estudantes adentrarem nesse nível educativo. Com a Lei 12.711 (BRASIL, 2012), conhecida como a "Lei de Cotas", o ingresso nas universidades federais passou por mudanças e diversificou ainda mais o público que acessa o ensino, com cotas raciais e reserva de vagas para sujeitos oriundos de ensino médio público.

Desse modo, um novo perfil de estudante passou a integrar a universidade brasileira e representar de forma mais próxima a diversidade do país em termos sociais e econômicos. Tal diversidade exige um novo modo de existir da universidade, com novos paradigmas e modos de produzir conhecimento científico e estratégias de apoio que fortaleçam a permanência e as condições de formação dos acadêmicos.

Diante do novo cenário da Educação Superior brasileira, compreende-se necessária uma leitura dinâmica e próxima da realidade do público que frequenta a graduação, que procura o apoio socioeconômico e de profissionais, especialmente para atender às necessidades que apresentam para permanecer estudando. Em meio a essa conjuntura, originou-se a inquietação que levou ao desenvolvimento da pesquisa de mestrado, que teve-se como propósito analisar os motivos enunciados por estudantes de uma instituição federal de Educação Superior para a procura pelo atendimento psicológico institucional na relação destes com o processo de ensino e aprendizagem.

A pesquisa apresentada por este artigo demonstra sua relevância e se justifica por vários aspectos, dentre eles, que o apoio psicológico na Educação Superior pública federal se mostra um trabalho relativamente novo no país e há escassa produção teórico-científica. Especialmente, estudos que se propõem a pensar o indivíduo enquanto ser que é afetado pelo meio social e por ele desenvolvido, considerando a unidade afetiva e cognitiva. Por isso, de desenvolver estudos nesta área possibilita qualificar constantemente os profissionais, produzir mais conhecimento para 
embasar a atuação e as intervenções apropriadas ao contexto e, ainda, permite agregar elementos para orientar políticas de assistência estudantil.

Esta pesquisa, de natureza bibliográfica e de campo, toma como fundamentação teórica a Psicologia Histórico-Cultural, em Vigotski ${ }^{1}$, Leontiev e Luria, pela condição de compreender o desenvolvimento do psiquismo a partir da aprendizagem nas relações sócio-históricas, bem como, a perspectiva bakhtiniana de linguagem, em Bakhtin e seu Círculo ${ }^{2}$, em que a linguagem é elemento constituinte do psiquismo humano, da consciência. Ambas as abordagens teóricas se orientam com base no materialismo histórico-dialético, que oferece fundamentação por meio da compreensão materialista da realidade.

A partir da introdução apresentada, parte-se para a discussão da fundamentação teórica que embasa a compreensão da realidade histórico-cultural humana, em seguida para a explicação do caminho metodológico percorrido e, por fim, a apresentação e discussão dos resultados.

\section{O desenvolvimento do psiquismo e a interação da linguagem}

A Psicologia Histórico-Cultural compreende que a apropriação da cultura e do trabalho, na vivência histórica, torna-se base para a constituição e o desenvolvimento do psiquismo humano. Esta consideração reporta-se a compreensão de que, embora as propriedades da espécie sejam reproduzidas em sua evolução filogenética, para Leontiev (2004), o desenvolvimento ontogênico humano ocorre pelas inter-relações com o meio, em que é possível a manifestação das propriedades específicas da espécie, regidas por leis sociais e históricas. Isso significa que o indivíduo torna-se ser social na medida em que as leis biológicas não o determinam, mas ao apropriar-se das leis sociais, daquilo que foi desenvolvido e acumulado ao longo do processo sócio-histórico, pela espécie humana.

Para explicar a influência social e cultural no desenvolvimento do psiquismo, Vygotski (1995, p. 150) formulou a "Lei genética geral do desenvolvimento cultural", para a qual "toda função no desenvolvimento cultural da criança aparece em cena duas vezes, em dois planos; primeiro no plano social e depois, no psicológico" (VYGOTSKI, 1995, p. 150 - tradução nossa). Com isso, Vigotski explicou que primeiramente a função do desenvolvimento aparece entre os homens, de forma interpsíquica, para, em seguida, passar ao interior da criança, tornando-se uma característica intrapsíquica.

Vygotski (1995) refere que apesar do aspecto biológico apresentar-se de forma mais constante, o desenvolvimento cultural acontece enquanto ocorrem também mudanças orgânicas no organismo. O diferencial na compreensão desse processo é que o desenvolvimento cultural está sobreposto ao crescimento e amadurecimento do desenvolvimento orgânico. Apesar de distintos, esses processos ligam-se de modo dialético.

Os conhecimentos historicamente elaborados pelo homem foram acumulados e transmitidos pelas gerações por meio da fixação exterior, ou seja, na atividade humana produtiva. Tal fixação ocorreu na objetivação desses conhecimentos, pela sua materialização. Por meio dos instrumentos criados pelo homem, que têm gravado neles modos de ação ou operações de trabalho,

\footnotetext{
${ }^{1}$ A grafia utilizada pelas autoras neste artigo é Vigotski, por se tratar da escrita mais próxima da língua portuguesa. Entretanto, no decorrer de todo o texto constam grafias diversas para nominar o autor, que estão de acordo com as obras consultadas como referência.

2 Denominação utilizada como referência para identificar Bakhtin e intelectuais ligados a seu grupo, que compartilhavam ideias e interesses filosóficos (FARACO, 2009, p. 13).
}

Práxis Educativa, Ponta Grossa, v. 16, e2118474, p. 1-16, 2021 
é possível apropriar-se daquilo que foi desenvolvido e acumulado no mundo ao seu redor, o que possibilita "[...] a reprodução pelo indivíduo, das aptidões e funções humanas, historicamente formadas[...]” (LEONTIEV, 2004, p. 180).

Como observa-se na concepção de Vygotski (1995), o comportamento de um adulto resulta dos processos biológicos da evolução e históricos da culturalização, portanto, as funções psicológicas superiores, desenvolvidas pelo sujeito, são produto da interiorização da ordem social e fundamento da estrutura social da personalidade.

Marino Filho (2007) ressalta que a atividade educativa é um processo social de desenvolvimento do homem, abarca o conhecimento histórico sobre o gênero humano e o transmite por meio do processo mediativo, gerando consciência e desenvolvimento em cada indivíduo. Tão logo, é fato que a mediação não ocorre na individualidade, mas sim em uma relação que se tenha finalidade e elementos que se inter-relacionem. A mediação acontece a partir das relações que se estabelecem e permitem a interação de diversos fatores, que desencadeiam uma trama de inter-determinações, e produz como resultado o desenvolvimento do sujeito em etapa a qual não havia atingido, em relação à consciência, aos processos cognitivos e à atividade.

Luria (1991), ao tratar especialmente da linguagem, também evidencia as relações sociais, assim como a cultura, e aponta que a linguagem é a segunda condição responsável pela formação da estrutura psíquica complexa do homem, auxiliando na formação da atividade consciente. A outra condição é o uso de instrumentos e do trabalho social.

De acordo com Vygotski (1997), a linguagem é instrumento psicológico e nela o signo se coloca enquanto meio de comunicação. Sob a perspectiva de Leontiev (2004, p. 184), "a linguagem é aquilo através da qual se generaliza e se transmite a experiência da prática sócio-histórica da humanidade [...]", também é um meio de comunicação que fornece condições para o processo de apropriação da experiência e da existência na consciência do indivíduo. O desenvolvimento que permite compreender e utilizar a linguagem é decorrente do processo de apropriação e formação de conceitos, fundamental na ontogênese e, consequentemente, na constituição do psiquismo humano.

Neste âmbito, os processos psíquicos são mais desenvolvidos por conta da linguagem e da consciência. A vida do homem torna-se consciente na medida em que reorganiza os processos de percepção do mundo. Nessa mesma perspectiva, a atuação da linguagem sobre os estados emocionais também proporciona mudanças que desenvolvem os processos psíquicos. O mundo emocional humano reflete nas vivências unidas ao pensamento e influenciadas pela linguagem, que são muito maiores do que reações afetivas ${ }^{3}$ (LURIA, 1991).

O signo, que referimos acima, em Vigotski é entendido como um mecanismo de relação social, um meio que exerce influência sobre os demais e acaba por transformar-se enquanto influência sobre si mesmo. No decorrer do desenvolvimento, a criança reproduz sobre si o comportamento que os outros aplicam a seu respeito, ou seja, ela assimila as formas sociais da conduta de modo a transferi-las para si. Essa condição se manifesta com o emprego dos signos (VYGOTSKI, 1995).

Desse modo, o signo é um estímulo artificial que desempenha função de auto-estimular, que o caracteriza com um sentido mais amplificado do que a palavra por si. Inserido pelo próprio homem em sua situação psicológica, o signo é introduzido como meio para orientar a conduta

\footnotetext{
${ }^{3} \mathrm{Na}$ abordagem teórica elencada, não há um consenso quanto a definição e o uso dos termos emoção e afeto. Assim, neste artigo utilizaremos os termos como sinônimos.
}

Práxis Educativa, Ponta Grossa, v. 16, e2118474, p. 1-16, 2021 
humana (VYGOSTSKI, 1995).

Perante o exposto, a Psicologia Histórico-Cultural possibilita compreender a complexidade do psiquismo humano em relação com linguagem, superando fundamentações teóricas restritivas, que tentaram explicá-lo de forma mais biológica ou idealista. Ao contrário, Vigotski bem como Luria e Leontiev, puderam identificar a influência de diversos elementos sociais e relacionais sobre o material biológico humano, mergulhado na cultura, essencialmente formado em um processo histórico.

Ao adentrar na literatura bakhtiniana, pode-se compreender a importância da linguagem para os sujeitos, além de sua articulação com a educação e os processos de ensino e aprendizagem. Percebe-se que o sujeito está situado e submetido a um contexto sócio-histórico e relacional, concebido em um complexo de interações em que é definido pelo outro que também o define. A constituição dialógica e a repercussão sobre o sujeito da ressonância discursiva dos outros sujeitos, que estabelece uma identidade subjetiva e em constante transformação, são elementos centrais (SOBRAL, 2010).

Nesse sentido, a linguagem incorpora importância enquanto elemento da concepção teórica de Bakhtin e o Círculo, fundamentada em categorias que lhe compõem e inserem sentido. Para Bakhtin e Volochínov (2014), a consciência do sujeito adquire sua existência através das relações sociais, que são nutridas pelos signos. Estes, por sua vez, são a materialização de uma forma de comunicação social, são a expressão de uma realidade representativa que comporta aspectos ideológicos, que refletem e refratam uma outra realidade, que se remete a algo fora de si.

Os signos, na perspectiva bakhtiniana, aparecem como elementos materiais do mundo que possuem função na vida social humana. Por serem oriundos das relações e ganharem significações que superam as características materiais que apresentam, incorporam valor e significado, tornamse muito mais do que um objeto diante das relações sociais, mas potencializam e com isso tornamse signos (MIOTELLO, 2010).

Além de seu sentido material e sócio-histórico, agrega-se ao signo aquilo que Miotello (2010, p. 170) descreve como "[...] "ponto de vista", pois representa a realidade a partir de um lugar valorativo [...]", no qual se encontram características valorativas e de sentido ideológico.

Nesse sentido, a palavra como componente da linguagem cumpre função de signo por ser o modo mais "[...] puro e sensível de relação social", é através dela que a comunicação social acontece, sendo "[...] na palavra que melhor se revelam as formas básicas, as formas ideológicas gerais da comunicação semiótica” (BAKHTIN; VOLOCHÍNOV, 2014, p. 36-37).

O fato da palavra assumir múltiplos significados, bem como de produzir sentidos diversos, de acordo com a intencionalidade do dito e a compreensão do interlocutor, torna-a um fator de análise indispensável para a compreensão subjetiva humana, na medida em que é capaz de carregar e expressar as particularidades da consciência do sujeito, advindas do encontro entre os sujeitos e seus posicionamentos valorativos que aspiram e reproduzem intencionalidade.

Se a palavra é um meio de expressão humana, entendemos que a linguagem deve ser objeto de análise social e individual, pois nela o conteúdo é materializado e estabilizado, é possível e passível de ser estudado para a compreensão daquilo que está além das palavras enquanto sistema linguístico. Pois, existem muitos elementos do contexto histórico, cultural, das relações vividas e compartilhadas socialmente que constituem a consciência do sujeito.

Nesse sentido, a pesquisa que deu origem a este artigo quando toma por objeto de estudo os estados emocionais dos estudantes na interação com o processo de ensino e de aprendizagem,

Práxis Educativa, Ponta Grossa, v. 16, e2118474, p. 1-16, 2021

Disponível em: < https:// revistas2.uepg.br/index.php/praxiseducativa $>$ 
demonstra a preocupação em compreender, pela perspectiva da linguagem em seus enunciados, aquilo que os sujeitos deixam manifestar da consciência e também expressar da sua subjetividade. Desta forma, os estados emocionais e os diversos fatores associados ao processo de ensino e de aprendizagem na Educação Superior podem ser identificados e levados em consideração na totalidade do contexto a que o sujeito se insere.

Conforme Bakhtin e Volochínov (2014, p. 37), a palavra é capaz de expressar a consciência individual, é meio de expressão do conteúdo, do discurso da vida interior do sujeito. Enquanto produto da interação social, tem papel de "signo interior", como manifestação interna da subjetividade do sujeito, produto por ele refletido e refratado.

Desse modo, compreende-se que é a partir da linguagem, a qual é muito mais do que troca de informações entre pessoas, mas também constituinte da consciência, que os homens se apropriam das características mais humanas, desenvolvem suas funções psicológicas mais específicas e, como consequência, passam a constituir-se subjetivamente. Outrossim, entende-se necessária e possível a compreensão das dificuldades e sofrimentos enunciados por estudantes universitários, público-alvo da pesquisa, ao emitirem um discurso implicado pela consciência e ligado ao contexto sócio-histórico e a realidade que vivem.

Pois ainda, conforme Bakhtin e Volochínov (2014, p. 52-53), “[...] todo pensamento, toda emoção, todo movimento voluntário, são exprimíveis [...]”. Esse apontamento dos autores indica que há uma relação entre a atividade psíquica e sua manifestação, portanto ela pode ser revelada ao meio externo e assim analisada.

\section{As emoções e o processo de ensino e aprendizagem}

A formação do psiquismo, segundo Martins (2016), ocorre na medida em que o homem se apropria das condições materiais e ideais produzidas pela própria ação humana. Ao interagir, esse processo conduz um ser hominizado, ainda quando apenas carrega as propriedades naturais da espécie, para um ser humanizado, quando já apropriou da cultura, por assim dizer, do produto histórico e socialmente formado.

A autora explica que o psiquismo pode ser compreendido como um reflexo subjetivo, uma imagem da realidade objetiva, resultado da evolução e revolução humana a partir da relação transformadora entre homem e natureza (MARTINS, 2015). A partir dessas considerações iniciais, direciona-se o foco de discussão para as emoções e os sentimentos, tendo como pressuposto que tanto na constituição do psiquismo infantil quanto na vida adulta, ambos afetam a existência humana. A esse respeito, Vygotski (1996) apresenta a tese de que a vida psíquica da criança é instintiva e se desenvolve pela influência de afetos e de outras atrações, sendo os impulsos afetivos acompanhantes do desenvolvimento em todas as suas etapas

Em sua obra, Vigotsky (2004) realiza a leitura das teorias de Lange e James sobre a natureza das emoções humanas, quando critica os equívocos das teorias, principalmente o fato de não conseguirem superar o dualismo cartesiano, o qual dicotomizava a compreensão do corpo e da mente, enfatizando a origem fisiológica dos estados psíquicos. Com isso, assinala Vygotsky (2001), as emoções foram tratadas de forma isolada, distanciadas da vida psíquica como um todo e, assim, foram explicadas de maneira anátomo-fisiológica.

Já, sobre Espinosa ${ }^{4}$, Vygotski (1997) explica que ele estava correto quando referiu que o

\footnotetext{
${ }^{4}$ Baruch de Espinosa nasceu em 1632, em um bairro judeu de Amsterdã, em uma família de comerciantes prósperos, de origem espanhola e portuguesa. Realizou estudos teológicos e comerciais na escola judia. Trabalhou desde os treze
}

Práxis Educativa, Ponta Grossa, v. 16, e2118474, p. 1-16, 2021 
homem tinha poder sobre os afetos, sendo que a razão poderia interferir na ordem e nas conexões afetivas a fim de concordarem com a razão. Para ele, o conhecimento que temos sobre nossos afetos é capaz de alterar, transformar a vida psíquica do sujeito, visto que atuam sobre o intelecto e sobre outras instâncias que se relacionam com o sistema de conceitos do sujeito.

Percebe-se assim que para Vygotsky (2001), o pensamento não está privado de momentos emocionais, ao contrário, apresenta reações consideráveis e intensas. Mas, Vigotski avança na elaboração de uma compreensão sobre as emoções a partir da perspectiva Histórico-Cultural, ou seja, explica a influência dos objetos externos sobre a consciência, apoiado nos fundamentos que até então utilizou para o desenvolvimento de sua teoria. Nessa compreensão, há uma unidade entre afetos, sentimentos e o pensamento, em que se torna necessário compreendê-los enquanto integrados por "interconexões" e não isoladamente (MARTINS, 2015, p. 73).

A importância das vivências no processo afetivo e da subjetividade humana aprofunda a compreensão integradora dos elementos que se relacionam com as emoções. Nesse sentido, Vigotski (2018) explica que a influência do meio para o desenvolvimento humano ocorre somente na relação entre o sujeito e o meio social. Pois é a relação que permeiam as mudanças que ocorrem no desenvolvimento e que fazem com que também sucedam modificações quanto ao papel e significados vivenciados no meio. A vivência torna-se o elo diferencial do processo de desenvolvimento psicológico, na medida em que incide sobre o sujeito na relação entre ele, que se encontra em uma determinada etapa de desenvolvimento, e o meio, no momento vivenciado que refrata sobre si.

Mas, em síntese, o que significa a vivência? Para Vigotski (2018, p. 78) a vivência corresponde a "uma unidade na qual se representa, de modo indivisível, por um lado, o meio, o que se vivencia [...] e, por outro lado, como eu vivencio isso" (grifos do autor), a partir das características de personalidade que se relacionam.

Por essa definição, a singularidade do que é experienciado pelo sujeito fica evidente, quando suas especificidades de personalidade entram em relação com o meio, ou seja, em relação com um determinado contexto social de desenvolvimento que pode ser comum a um coletivo. Assim sendo, cada sujeito vivencia a seu modo uma dada situação. Em tese, explica-se por esta via a razão pela qual diferentes estados emocionais são desencadeados e manifestados por sujeitos diante de um mesmo acontecimento.

Portanto, para Vygotski (1996) o afeto está essencialmente envolvido com o processo de desenvolvimento do psiquismo, de tal modo que se altera a cada novo momento da formação da personalidade. Nesse movimento, o afeto ganha espaço na estrutura da consciência, que também se modifica ao desenvolvimento do ser humano.

Assim sendo, o homem estrutura seu psiquismo a partir de condições objetivas da realidade que interagem e permitem a formação das funções psicológicas superiores. Toda essa relação com a realidade, interior e exterior, demanda-lhe a apropriação dos conhecimentos do mundo, que carregam consigo repercussões emocionais (MARTINS, 2015).

Para Martins (2013) a compreensão da dinâmica relação entre o afeto e as funções cognitivas - linguagem, sensação, atenção, memória, percepção, pensamento, imaginação - é essencial, pois destaca que a unidade afeto-cognição pressupõe a "emoção como dado inerente ao

anos nos negócios da família. Foi excomungado em 1656 da comunidade judaica e por romper com o meio religioso, da mesma forma rompeu com o econômico, abandonou os negócios do pai e aprendeu o ofício de artesão. $\mathrm{O}$ cartesianismo foi utilizado por Espinosa como retórica, nunca foi um pensamento por ele defendido (DELEUZE, 2002).

Práxis Educativa, Ponta Grossa, v. 16, e2118474, p. 1-16, 2021 
ato cognitivo uma vez que nenhuma emoção ou sentimento e, igualmente, nenhum ato do pensamento, podem se expressar como "conteúdos puros", isentos um do outro [...]" (MARTINS, 2013, p. 244). Por assim dizer, indica que há uma interação intrínseca e recíproca entre emoções e as demais funções cognitivas do sistema psíquico humano.

À luz da Psicologia Histórico-Cultural, Gomes e Mello (2010) discutem que o afeto é elemento que mobiliza o sujeito e lhe desperta reações. As autoras sinalizam que a vivência de um afeto promove alterações no sujeito, especialmente em seu modo de pensar, sentir e agir, que geram um potencial atitudinal em relação aos objetos.

Desse modo, compreende-se que as emoções humanas adquirem transformações qualitativas, emergem no processo social e não encontram finitude, ou seja, manifestam-se durante toda a vida, em constante interação com o meio social. Nesse sentido, o sujeito é afetado ao longo de sua vida, e por isso, inclusive quando se encontra no meio acadêmico na educação superior, período esse que já pressupõe diversas mudanças sociais, pessoais e relacionais que se vinculam à experiência do momento de vida.

Martins (2016) atribui o papel da educação escolar como de promover as objetivações culturais a fim de que cada indivíduo realize suas apropriações. A aprendizagem é, portanto, geradora de desenvolvimento e, conforme define Vygotsky (2005), o processo de desenvolvimento segue o processo da aprendizagem, ou seja, não ocorrem concomitantemente. Nesse sentido, o autor aponta que entre estes processos existe uma dependência que se caracteriza como recíproca, complexa e dinâmica.

Para Martins (2013), Vigotski direciona o entendimento para além da ideia de ensinar a criança. Para autora, o que está colocado na teoria é o espaço de desempenho entre os limites e as possibilidades da criança, quando a superação de limites abre caminhos para novas possibilidades.

Entende-se, pois, que na medida em que o sujeito possui determinadas capacidades, tem condições potenciais de apropriar-se de novas e se desenvolver. Para esse processo tornar-se efetivo, exige o envolvimento de um outro nesta relação, que ajude, auxilie, realize a mediação na direção do novo desenvolvimento e sua posterior independência (MARINO FILHO, 2007).

Diante do exposto, observa-se que existe um conjunto de influências externas que recaem sobre o indivíduo por meio da consciência; são reflexos que incidem e propiciam emoções a partir das variáveis que fazem com que se constituam e despertem. Considerando a análise de Vigotski (2018), este estudo, relativo aos estados emocionais envolvidos no processo de ensino e aprendizagem no ensino superior, apresenta e explicita a natureza diversa e a variabilidade daquilo que está relacionado com as emoções manifestadas pelos estudantes ao buscarem o atendimento psicológico, bem como, a vinculação destas com a aprendizagem. Percebe-se assim, que a vivência tem papel fundamental no processo de desenvolvimento psicológico.

\section{Percurso metodológico}

A coleta de dados ${ }^{5}$ ocorreu em um campus localizado no interior do Paraná - BR, de uma instituição universitária federal e multicampi. A universidade, lócus da pesquisa de campo, utilizava como método de acesso o Sistema de Seleção Unificada - Sisu e a distribuição de vagas conforme a Lei de Cotas. Aproximadamente $90 \%$ de suas vagas eram ocupadas por estudantes que cursaram

\footnotetext{
5 Projeto de pesquisa submetido e aprovado pelo Comitê de Ética em Pesquisa, sob número CAAE 71197717.7.000.0107 - Parecer 2.195.227.
}

Práxis Educativa, Ponta Grossa, v. 16, e2118474, p. 1-16, 2021 
o ensino médio em escolas públicas, sendo provenientes das mais diversas regiões do Brasil, o que denota a diversidade do público estudantil presente no âmbito da instituição.

Por meio de 30 questionários aplicados aos estudantes que buscavam, por livre procura, o atendimento psicológico na universidade, os dados foram obtidos, posteriormente tabulados e submetidos à metodologia da análise de conteúdo de Bardin (2011). Utilizou-se o critério semântico que considera a organização dos dados em categorias temáticas que apresentam determinado significado e, portanto, podem ser condensados e representados em seus dados brutos. As categorias temáticas foram analisadas à luz da Psicologia Histórico-Cultural e Bakhtiniana de linguagem referenciada.

\section{Análise do conteúdo e considerações finais}

A partir da análise de conteúdo realizada, com o objetivo de identificar os motivos que levavam estudantes universitários a buscar atendimento psicológico na instituição de ensino, emergiram quatro categorias temáticas: mudanças na condição de vida; adaptação acadêmica/escolha profissional; impacto/reações emocionais; e, processo de ensino e de aprendizagem. Verificou-se que a grande maioria das razões manifestadas pelos estudantes foram associadas a dificuldades emocionais que interferiram no processo de aprendizagem. Na sequência, e com significativa expressividade, foram indicados como motivos as dificuldades de aprendizagem que influenciaram emocionalmente.

As dificuldades emocionais, como principal motivador do atendimento psicológico, representam $76,66 \%$ das respostas dos participantes da pesquisa. Os estudantes manifestaram seus sentimentos e demonstraram, desta forma, o conteúdo subjetivo que perpassa pelas vivências a que se depararam na Educação Superior, o que foi possível através do questionário que materializou a linguagem exteriorizada daquilo que é sentido pelos estudantes, conforme a perspectiva baktiniana de linguagem propõem.

Tecer análises sobre os enunciados dos sujeitos exige a observância da vida em sua totalidade, compreendida a partir de quem manifesta sua consciência de mundo em relação ao lugar que ocupa historicamente, o momento e as experiências já vivenciadas. Nesse sentido, os enunciados dos estudantes são carregados pela consciência de sua existência, atravessada pelas relações sociais manifestas pelos signos, que, por sua vez são a materialização da comunicação social (BAKHTIN; VOLOCHÍNOV, 2014). Logo, a linguagem comporta elementos que traduzem sentido, sendo expressão da realidade que alude a algo fora de si, mas que ecoa subjetivamente em uma relação dialógica e dialética.

Com a análise da linguagem, verificou-se que são diversos os fatores que se colocaram como atuantes na condição emocional dos estudantes. Muitos destes fatores evidenciados foram desencadeados a partir das mudanças inerentes ao ingresso na Educação Superior, ou seja, um novo processo educativo, com novas cobranças, mudança de cidade, distância de figuras importantes como familiares, questões de relacionamento, em especial, associadas a relação com colegas e docentes, e a adaptação a toda esta nova realidade.

É preciso considerar, conforme explica Vigotski (2018), que as vivências têm potencial de desenvolvimento humano, ao passo que o meio entra em relação com o sujeito. As mudanças ocorrem a partir das vivências; advêm de um sujeito em determinada etapa de desenvolvimento que interaciona com este meio, com o contexto com que se depara, e que, recaindo sobre esse mesmo sujeito, influencia seu processo de desenvolvimento psicológico. A importância de destacar estes aspectos está em demonstrar que todas as experiências e vivências repercutem sobre o

Práxis Educativa, Ponta Grossa, v. 16, e2118474, p. 1-16, 2021

Disponível em: <https:// revistas2.uepg.br/index.php/praxiseducativa> 
indivíduo, entram em dinâmica interação com sua subjetividade e reconfiguram o conteúdo que ali se apresenta, transformando-o continuamente, um sujeito que se mantêm em constante desenvolvimento.

Assim, mostraram-se existentes reações emocionais que decorreram da necessidade de assumir novas responsabilidades, conviver com pessoas pouco conhecidas, sendo que a grande maioria passou a residir com colegas universitários. Todo este contexto se relaciona com a adaptação acadêmica, por parte tanto do estudante quanto da instituição de ensino. Desta forma, a manifestação de participantes da pesquisa que vivenciaram dificuldades relacionais e que estas afetaram sua aprendizagem, na medida em que repercutiram sobre seu estado emocional, evidencia que todo o sujeito que interage com o estudante no processo de ensino-aprendizagem tem papel importante. A exemplo dos professores, que assumem a condição de mediar o conhecimento e assim, a reação emocional que este processo acaba por provocar no estudante pode tanto favorecer quanto interferir desfavoravelmente em sua aprendizagem.

Pois, vejamos que, conforme Leontiev (2004) o papel mediador é fundamental no processo de ensino e aprendizagem, na medida em que a consciência humana é concebida de significações adquiridas no curso das experiências, portanto é reflexo assimilado e transformado. Para o autor, sendo os processos psíquicos envolvidos pela mediação de estímulos sociais, o sujeito se apropria das atividades pela via da inter-relação e as internaliza, tal como no processo de ensino em que o ato de mediar reflete sobre o psiquismo humano e na consciência do sujeito sobre a realidade.

No entanto, apesar dos aspectos emocionas influentes sobre o processo de aprendizagem terem sido percebidos e apontados pelos estudantes como aqueles que mais lhes motivaram a buscar o atendimento psicológico, a relação inversa também foi representativa. Isto quer dizer, que também houve um número expressivo de $43,33 \%$ dos estudantes que evidenciaram que os fatores do processo de aprendizagem influenciaram sobre a condição emocional, como motivador para a busca de atendimento psicológico institucional.

Este resultado faz-se importante ao passo que trazemos uma análise dialética, integradora, em que compreendemos que há uma relação intensa e próxima entre estes dois elementos, emoções e aprendizagem, ambos se afetam. A relação prejudicada entre estes, tende a causar sofrimento e ser fonte de sintomas, dentre os quais remetem ao distanciamento e a prejuízos no processo de aprender, bem como na saúde do estudante.

Também, percebeu-se por meio da pesquisa que a adaptação acadêmica e questões relacionadas à escolha profissional, ou seja, opção pelo curso universitário, incidem de forma importante e causam sofrimento aos estudantes. A análise realizada demonstrou que são percebidas alterações emocionais, ou seja, há um impacto psíquico que se coloca envolvido na condição de estar e de permanecer na universidade de forma satisfatória, além de afetar outras áreas como a apropriação de conhecimento, no processo de aprendizagem.

O atendimento psicológico pode auxiliar e favorecer a percepção da nova realidade vivenciada pelo estudante universitário, na medida em que ajuda a torná-la mais consciente. Conforme explica Luria (1991), há um mundo emocional no sujeito que reflete suas experiências vivenciadas, por meio do pensamento e pela influência da linguagem. Os processos psíquicos são desenvolvidos nessa interação da linguagem e da atividade sobre os estados emocionais. Com isso, o autor considera que o sujeito toma consciência de sua vida ao passo que reorganiza seus processos de percepção do mundo. De tal modo, podemos ainda dizer que o atendimento psicológico contribui para o desenvolvimento da função psicológica superior emocional, que passa a ser mediada neste processo. 
Pesquisadores já constataram que as ações da política de assistência estudantil direcionadas ao suporte financeiro oferecem condições de permanência no Ensino Superior, todavia outras iniciativas precisam ser praticadas. Pois, a permanência perpassa por vários fatores que ultrapassam as necessidades financeiras, como exemplo do apoio no processo de ensino-aprendizagem (SCHER, 2017, SOUZA, 2016, FREITAG, 2014).

Dentre os participantes da pesquisa, a procura pelo atendimento psicológico foi maior por aqueles estudantes que não são recebedores de auxílios socioeconômicos institucionais, portanto, se mostrou superior para aqueles alunos considerados menos vulneráveis socioeconomicamente. Pelo exposto, este resultado demonstra que, apesar de o sofrimento humano ser multifatorial e se manifestar em situações de vulnerabilidades sociais e financeiras, o sofrimento emocional também está ligado a outros fatores.

Para tanto, as instituições de Educação Superior necessitam agir diante desses aspectos como forma de favorecer a permanência e evitar a evasão dos seus acadêmicos, posto que os relatos dos estudantes apresentaram sentimentos de abandono ou, ainda, de dificuldade de enfrentamento das exigências universitárias. Teixeira et al (2008) enfatizam que tratar de adaptação ao curso superior depende de um conjunto de fatores tais como os vínculos afetivos, tanto entre colegas quanto com professores, atividades extra sala de aula e estratégias para enfrentar frustrações e dificuldades.

O sofrimento presente nos enunciados dos sujeitos da pesquisa esteve manifestado em sintomas e também, de forma velada, nas verbalizações de vivências angustiantes. Nesse sentido, compreende-se que o trabalho do psicólogo na educação também deve estar direcionado para apoiar a identificação dos fatores ligados ao sofrimento dos estudantes, que afetam a aprendizagem e, por consequência, seu desenvolvimento, que vertem da condição histórico-social e do contexto mais imediato a que foram e estão expostos.

Sobre as dificuldades emocionais afetarem o sujeito, Martins (2013) considera que as vivências experimentadas pelo sujeito o afetam, transformam suas atitudes, e por assim ser, são concebidas como vivências afetivas. Podemos constatar que a vivência universitária dos participantes de nossa pesquisa em alguma medida lhes afetou, ao passo que manifestam diversos estados emocionais relacionados à procura por atendimento psicológico, decorrentes da experiência universitária.

O trabalho do psicólogo na Educação Superior pode favorecer a reflexão e a compreensão da condição a que vive o estudante e que lhe repercute emocionalmente. Ressalta-se a importância da articulação com os diversos profissionais que se dedicam a estas questões, em âmbito universitário, com destaque aos envolvidos na execução do PNAES. Faz-se essencial que ações de política estudantil sejam planejadas continuamente e intervenções sugeridas, a fim de que o estudante seja acolhido e permaneça na universidade, com condições para se sentir pertencente àquele espaço e, assim, melhor aproveitar e apropriar-se da formação ofertada em nível superior.

Diante dos dados da pesquisa, a análise revela que estados emocionais de tristeza, ansiedade, medo e dificuldades de atenção e concentração foram os mais referidos pelos participantes do estudo. No entanto, ao todo foram mais de 30 menções a algum tipo de emoção ou comportamento que estiveram associadas com a motivação para procurar pelo atendimento psicológico. Estes dados demonstram que há presença importante, e que precisa ser reconhecida, sobre o que vivenciam emocionalmente estes sujeitos, ao passo que as implicações sobre o processo de aprendizagem mostraram-se presentes. Conforme Vigotski (2018), toda vivência representa a unidade entre o sujeito e o meio, havendo a integração do que o meio apresenta e do modo particular de cada sujeito vivenciar, que considera suas características de personalidade. Destarte, a

Práxis Educativa, Ponta Grossa, v. 16, e2118474, p. 1-16, 2021 Disponível em: < https://revistas2.uepg.br/index.php/praxiseducativa> 
vivência afeta o sujeito, apresentando modos particulares de sentir e retratar a experiência, como representaram os estudantes.

Outro resultado importante diz respeito a forma como os estudantes percebem a responsabilidade sobre seu estado emocional, quando houve autoprojeção, ou seja, os relatos revelam que de forma significativa os estudantes atribuem a si a responsabilidade pelas dificuldades emocionais que apresentam enquanto universitários. No entanto, ao compreendermos o sujeito em sua constituição sócio-histórica, sabemos que os processos não são unilaterais, a aprendizagem ocorre em uma relação mediada, tão logo, permeada pelo "outro" que também incide sobre aquilo que afeta o sujeito.

A partir de uma maioria dos sujeitos da pesquisa que atribuiu a si a responsabilidade sobre o sofrimento que vivencia, percebemos uma compreensão distorcida sobre a dinâmica dos processos de ensino e aprendizagem e da responsabilidade sobre a ambientação ao contexto universitário. Com isso, ressaltamos a contribuição de Espinosa referida por Vygotski (1997) de que o conhecimento que adquirimos sobre nossos afetos têm a condição de transformar $o$ psiquismo humano, na medida em que se relaciona com o sistema de conceitos do sujeito. Assim, a forma de responsabilizar a si quanto a sua condição emocional, como manifestaram diversos estudantes da pesquisa, denota a compreensão que apropriaram no contexto social a que se submeteram historicamente, reduzindo ao sujeito e se auto-culpabilizando.

Todos estes resultados mostram que os jovens universitários experimentam uma mudança significativa de vida na ocorrência do ingresso no ensino superior que lhes afetam; deparam-se com uma nova organização institucional educativa, com alterações culturais, sociais, econômicas e relacionais que podem ser fatores desencadeantes de reações emocionais, estas que inclusive incidem sobre o processo de aprendizagem.

Verifica-se desta forma, que se faz necessário e um diferencial na Educação Superior, as ações que promovam acolhimento, integração e adaptação ao estudante, bem como que a instituição se prepare e se reorganize para prover os estudantes no ingresso e ao longo do tempo de permanência, a partir do perfil destes sujeitos. Pois, sabe-se que as mudanças são influenciadas pelas vivências de um sujeito que se encontra em uma determinada etapa de desenvolvimento, ou seja, a qualidade das experiências vividas pelo estudante em sua estadia na Educação Superior se liga com os estados emocionais apresentados por eles e recai sobre o processo de aprendizagem.

Nesse sentido, as emoções tornam-se resultado gerado no processo educativo, quando entendemos em perspectiva histórico-cultural que o sujeito é afetado pela internalização das relações e pela apropriação do conhecimento. Nesta dinâmica internalização, conforme aponta Martins (2013), o sujeito é afetado, ou seja, os componentes afetivos inevitavelmente se colocam em meio ao processo. Por assim ocorrer, fica evidente que todo e qualquer processo de apropriação é permeado por emoções, de modo que reconhecer seu papel neste meio é também reconhecer o sujeito desta relação.

Em síntese, considera-se que há elementos diversos, tanto dos sujeitos quanto do contexto universitário e social, e, para além desses, que incidem sobre a condição emocional dos estudantes e interagem de forma importante, ou mesmo, determinante sobre o processo de aprendizagem. Logo, agir sobre este cenário é preciso, a fim de favorecer que a permanência na Educação Superior seja possibilitada e com qualidade. Especialmente, com a intenção de reforçar e fortalecer a fundamental importância que deve ser atribuída às emoções, que atravessam o percurso da vida humana como um todo, e, portanto, também na etapa de formação educacional e humana que corresponde ao Ensino Superior, com todas as suas peculiaridades.

Práxis Educativa, Ponta Grossa, v. 16, e2118474, p. 1-16, 2021 Disponível em: < https:// revistas2.uepg.br/index.php/praxiseducativa $>$ 


\section{Referências}

BAKHTIN, M. M.; VOLOCHÍNOV. V. N. Marxismo e filosofia da linguagem. Tradução de Michel Lahud e Yara Frateschi Vieira. 16. ed. São Paulo: Hucitec, 2014.

BARDIN, L. Análise de conteúdo. Tradução de Luís Antero Neto e Augusto Pinheiro. São Paulo: Edições 70, 2011.

BRASIL. Decreto $\mathbf{n}^{\mathbf{0}} \mathbf{6 . 0 9 6}$, de 24 de abril de 2007. Institui o Programa de Apoio a Planos de Reestruturação e Expansão das Universidades Federais - REUNI. Brasília, DF: 2007a. Disponível em: http://www.planalto.gov.br/ccivil_03/_ato2007-2010/2007/decreto/d6096.htm. Acesso em: 01 maio de 2018.

BRASIL. Portaria Normativa $\mathbf{n}^{\circ}$ 39, de 12 de dezembro de 2007. Institui o Programa Nacional de Assistência Estudantil - PNAES. Brasília, Ministério da Educação, 2007b. Disponível em: http://portal.mec.gov.br/arquivos/pdf/portaria_pnaes.pdf. Acesso em: 14 jun. de 2018.

BRASIL. Ministério da Educação - MEC. Relatório do primeiro ano - Reuni 2008. Programa de apoio a planos de reestruturação e expansão das Universidades Federais. 2009. Brasília, DF, 2009.2 Disponível em: http:/ / portal.mec.gov.br/index.php?option $=$ com_docman\&view $=$ download\&alias $=2069$-reunirelatorio-pdf\&category_slug=dezembro-2009-pdf\&Itemid=30192. Acesso em: 01 maio de 2018.

BRASIL. Decreto $\mathbf{n}^{\mathbf{0}} \mathbf{7 . 2 3 4}$, de 19 de julho de 2010. Dispõe sobre o Programa Nacional de Assistência Estudantil -PNAES. Brasília, DF, 2010. Disponível em: http://www.planalto.gov.br/ccivil_03/_Ato2007-2010/2010/Decreto/D7234.htm. Acesso em: 14 jun. de 2018.

BRASIL. Análise sobre a expansão das universidades federais 2003 a 2012. Relatório da Comissão Constituída pela Portaria no 126/2012. Brasília, DF, 2012. Acesso em: 21 abril de 2018. Disponível em: http://portal.mec.gov.br/index.php?option $=$ com_docman\&view $=$ download\& alias $=12386$-analise-expansao-universidade-federais-2003-2012-pdf\&Itemid=30192. Acesso em: 01 maio de 2018.

BRASIL. Ministério da Educação. Secretaria de Educação Superior - MEC/SESu. A democratização e expansão da educação superior no país: 2003 - 2014. 2014. Disponível em: http://portal.mec.gov.br/sesu-secretaria-de-educacao-superior/arquivos. Acesso em: 14 jun. de 2018.

DELEUZE, G. Espinosa: filosofia prática. São Paulo: Escuta, 2002.

FARACO, C. A. Linguagem e diálogo: as ideias linguísticas do Círculo de Bakhtin. São Paulo: Parábola Editorial, 2009.

FONAPRACE - Fórum Nacional de Pró-Reitores de Assuntos Comunitários e Estudantis. IV Pesquisa do perfil socioeconômico e cultural dos estudantes de graduação das instituições federais de ensino superior brasileiras. Centro de Estudos, Pesquisas e Projetos Econômicossociais - CEPEs. 2014. Uberlândia - MG, 2016. Disponível em: http://www.andifes.org.br/wpcontent/uploads/2017/11/Pesquisa-de-Perfil-dos-Graduanso-das-IFES_2014.pdf . Acesso em: 01 maio de 2018.

FREITAG, B. E. B. Políticas para permanência discente: implementação e consolidação na UTFPR Campus Pato Branco. 2014. Dissertação (Mestrado em Desenvolvimento Regional) - 
Universidade Tecnológica Federal do Paraná, Pato Branco, 2014.

GOMES, C. A. V.; MELLO, S. A. Educação escolar e constituição do afetivo: algumas considerações a partir da Psicologia Histórico-Cultural. Perspectiva, Florianópolis, v. 28, n. 2, p. 677-694, jul./dez., 2010. DOI: https://doi.org/10.5007/2175-795X.2010v28n2p677

LEONTIEV, A. O desenvolvimento do psiquismo. Tradução de Rubens Eduardo Frias. 2. ed. São Paulo: Centauro, 2004.

LURIA, A. R. Curso de Psicologia Geral - Introdução Evolucionista à Psicologia. Volume I. 2. ed. Tradução Paulo Bezerra. Rio de Janeiro: Editora Civilização Brasileira S. A., 1991.

MARINO FILHO, A. Relações de poder e dominação no processo educativo. 2007. Dissertação (Mestrado em Educação) - Faculdade de Filosofia e Ciências, Universidade Estadual Paulista, Marília, 2007.

MARTINS, L. M. O desenvolvimento do psiquismo e a educação escolar: contribuições à luz da psicologia histórico-cultural e da pedagogia histórico-crítica. Campinas: Autores Associados, 2013.

MARTINS, L. M. A formação social da personalidade do professor: um enfoque vigotskiano. 2. ed. Campinas: Autores Associados, 2015.

MARTINS, L. M. Psicologia histórico-cultural, pedagogia histórico-crítica e desenvolvimento humano. In: MARTINS, L. M.; ABRANTES, A. A.; FACCI, M. G. D. (org.). Periodização histórico-cultural do desenvolvimento psíquico: do nascimento à velhice. Coleção Educação Contemporânea. Campinas: Autores Associados, 2016. p. 13-34.

MIOTELLO, V. Ideologia. In: BRAIT, B. (org.). Bakthin: conceitos-chave. $4^{\mathrm{a}}$ ed. $4^{\mathrm{a}}$ reimpressão. São Paulo: Contexto, 2010. p. 167-176.

SCHER, A. J. Acesso e permanência estudantil na Universidade Federal da Fronteira Sul Campus Realeza-PR: uma equação possível? 2017. Dissertação (Mestrado em Serviço Social) Universidade Estadual do Oeste do Paraná, Toledo, 2017.

SOBRAL, A. Ato/atividade e evento. In.: BRAIT, B. (org.). Bakthin: conceitos-chave. 4. ed. $4^{a}$ reimpressão. São Paulo: Contexto, 2010. p. 11-36.

SOUZA, D. G. Acesso e permanência na UFPR: uma análise da política de assistência estudantil (2010 - 2014). 2016. Dissertação (Mestrado em Educação) - Universidade Federal do Paraná, Curitiba, 2016.

TEIXEIRA, M. A. P.; et al. Adaptação à universidade em jovens calouros. Revista Semestral da Associação Brasileira de Psicologia Escolar e Educacional (ABRAPEE), São Paulo, v. 12, n. 1, p. 185-202, jan./jun., 2008.

VYGOTSKI, L. S. Problemas del desarrollo de la psique. Obras Escogidas. Tomo III. Madrid: Visor, 1995.

VYGOTSKI, L. S. Psicología infantil. Obras Escogidas. Tomo IV. Madrid: Visor, 1996.

VYGOTSKI, L. S. Problemas teóricos y metodológicos de la Psicología. Obras Escogidas. Tomo I. Madrid: Visor, 1997. 
VYGOTSKY, L. S. Problemas de psicologia general. Obras Escogidas. Tomo II. Madrid: A Machado Libros S. A., 2001.

VIGOTSKY, L. S. Teoría de las emociones: estudio histórico-psicológico. Tradução Judith Viaplana. Madrid: Ediciones Akal, 2004.

VYGOTSKY, L. S. Aprendizagem e desenvolvimento Intelectual na idade escolar. In: VYGOTSKY, L. S.; LEONTIEV, A.; et al. Psicologia e pedagogia: bases psicológicas da aprendizagem e do desenvolvimento. Tradução Rubens Eduardo Frias. 7. reimpressão. 3. ed. São Paulo: Centauro, 2005.

VIGOTSKI, L. S. Sete aulas de L. S. Vigotski sobre os fundamentos da pedologia. Organização e tradução Zoia Prestes, Elizabeth Tunes. Tradução de Cláudia da Costa Guimarães Santana. 1. ed. Rio de Janeiro: E-Papers, 2018.

Recebido em 18/07/2021

Versão corrigida recebida em 11/10/2021

Aceito em 14/10/2021

Publicado online em 19/10/2021 